Archived version from NCDOCKS Institutional Repository http://libres.uncg.edu/ir/asu/

\title{
Appalachl̈ăn
}

B O O N E, N O R T H C A R O L I N A

\section{The Antecedents Of Moral Imagination In The Workplace: A Social Cognitive Theory Perspective}

\author{
Authors \\ Whitaker, Brian \& Godwin, Lindsey
}

\begin{abstract}
As corporate scandals proliferate, organizational researchers and practitioners have made calls for research providing guidance for those wishing to influence positive moral decision-making and behavior in the workplace. This study incorporates social cognitive theory and a vignette-based cognitive measure for moral imagination to examine (a) moral attentiveness and employee creativity as important antecedents of moral imagination and (b) creativity as a moderator of the positive relation- ship between moral attentiveness and moral imagination. Based on the results from supervisor-subordinate dyadic
\end{abstract}

Whitaker, Brian \& Godwin, Lindsey(2013) "The Antecedents Of Moral Imagination In The Workplace: A Social Cognitive Theory Perspective" Journal of Business Ethics (114.61) \{DOI\} 10.1007/s10551

Version Of Record Available At www.springer.com 
Introduction

Recent high-impact corporate scandals have reminded companies of the severe consequences of separating corporate agendas from social values, resulting in increased pressure for organizations to minimize immoral employee behavior (Treviño et al. 2006; Sekerka et al. 2009; Wagner and Dittmar 2006). Because of this resurgent focus on understanding and preventing corporate malfeasance, much research has been devoted to explicating models of workplace misconduct (Anand et al. 2004; Andreoli and Lefkowitz 2009; Marcus and Schuler 2004; Treviñ o and Weaver 2001). However, there has been a growing call from the field of positive organizational scholarship, informed by the rise of the positive psychology movement, that more research attention should be directed toward exploring the contextual and intrapersonal attributes that contribute to individual strengths rather than deficits if we are to foster organizational systems that actualize human potential (Cameron et al. 2003; Seligman et al. 2005). As such, the current research agenda for exploring ethical behavior in organizations is characterized by increasing appeals for studies that can help derive organizational-level prescriptions for positively influencing individual-level morality and moral motivation (Bright et al. 2006; Luthans and Avolio 2009; Wright and Quick 2009). Accordingly, the current study seeks to explore important determinants of moral imagination in the workplace.

Werhane $(1998,1999,2002)$ developed strong theoretical arguments for moral imagination - a form of specialized moral reasoning that reflects one's ability to understand a context from a number of different stakeholder perspectives, actualize new context-independent possibilities, and instigate the process of evaluating possibilities from a moral point of view. This conceptualization is in accord with decision-making researchers who have proposed that the capacity for moral reasoning is largely guided by conceptual schema that delineate the number of behavioral alternatives from which to choose when confronted with an ethically charged situation (Ashkanasy et al. 2006; Treviño and Brown 2004). Together these assertions indicate that those most capable of making good moral decisions are 
those who can generate a range of possible solutions when faced with an ethical ${ }^{1}$ dilemma.

Behavioral ethics scholars argue that the moral imagination construct represents a critical ability for innovative moral employee decision-making and suggest that its exercise assists employees in avoiding questionable activities by enabling employees to create decision models that contribute positively to corporate and social well-being (Caldwell and Moberg 2007; Moberg and Seabright 2000; Werhane 1998, 1999, 2002). Despite much theoretical work postulating the antecedents of moral imagination in organizations, such discourses have largely been inferential and conceptual in nature (Godwin 2006). Based on this relative dearth of empirical findings, the current study serves two purposes. First, building on the theoretical work of moral imagination scholars (Caldwell and Moberg 2007; Moberg and Seabright 2000; Werhane 1998, 1999, 2002), this study provides one of the first empirical explorations of moral imagination as a theoretical construct. Second, drawing upon social cognitive theory (SCT) (Fiske and Taylor 1991), we identify two important antecedents of moral imagination: an individual's level of moral attentiveness and their capacity for creativity. This research adds to the literature on moral decision-making in organizations. Developing a better understanding of the antecedents of moral imagination in the workplace has important implications for organizational practitioners, business ethics researchers, and, by extension, the greater society within which organizations are embedded.

\section{Moral Imagination}

The concept of moral imagination is not new, appearing often in literary theory. While analogous to Kohlberg's (1976) post-conventional stage of moral reasoning (wherein individuals prioritize equity, perspective-taking, and decision-making according to the universal principles of morality rather than societal laws and values), moral imagination is drawn from a pragmatic conceptualization of moral understanding. Pragmatist ethics focuses on the day-to-day life-experiences of individuals who are socially and historically embedded (Fesmire 2003; Krebs and Denton 2005). This perspective emphasizes an understanding of problems and their resolution while rooted in this context. This is in contrast to the deontological perspective of cognitive developmental research on morality

\footnotetext{
${ }^{1}$ While we recognize that the terms ethical and moral have somewhat different connotations, for purposes of this article, we will use the terms interchangeably, with both referring to a utilitarian view where an action is presumed to be "better" or more desirable when it benefits more people (i.e., stockholders and other stakeholders in society).
}

that focuses on abstract moral principles. The pragmatist approach allows for the fact that there are multiple factors at play in moral situations. Thus, this approach speaks to the problem-oriented needs of the business practitioner (Frederick 2000) and organizational stakeholders. It is from the pragmatists' school of thought that moral imagination has emerged as a framework for the study of moral reasoning and ethical decision-making in organizations.

In their application of moral imagination to organizational decision-making, authors have conceptualized this construct in slightly different ways (Caldwell and Moberg 2007; Moberg and Seabright 2000; Werhane 1998, 1999, 2002). However, the common theme underlying each conceptualization is that moral imagination is a requisite com- ponent of responsible moral judgment as it enables one to disengage from a situation in order to consider new possibilities and evaluate these possibilities in terms of their moral worth and potential for positive impact. Because mental models used for decision-making are socially constructed, incomplete, and flexible with regard to their application (Rest 1986), they can be strategically modified to facilitate sounder moral judgment by those predisposed to think about moral concerns. In contrast to employees who approach ethical problems using limited mental models governed by partial perspectives (e.g., rule-based concerns), morally imaginative employees have the ability to disengage from such mental models to actualize context-independent possibilities and evaluate both the status quo and newly formulated possible outcomes from a moral standpoint.

Based upon the philosophical works of Smith (1776/ 1977) and Kant (1781/1970), Werhane (1998) encapsulated and crystallized the definition of moral imagination by proposing it as a process that involves "at least four things: (1) that one disengage oneself from one's role, one's particular situation, or context; (2) that one becomes aware of the kind of scheme one has adopted and/or that is operating in a particular kind of context; (3) that one creatively envision new possibilities, possibilities for fresh ways to frame experiences and new solutions to present dilemmas; and (4) that one evaluate the old context, the scope, or range of the conceptual schemes at work, and new possibilities.' In other words, moral imagination encompasses not only awareness of the moral implications of one's actions in a situation, but also an ability to reframe a situation and create moral alternatives to the situation at hand. An individual must first be able to perceive or distinguish the moral issues in a situation, including their impact on others beyond themselves, before they can generate decision options that take into account concerns of others. If one does not "encode," or remains unaware of, the moral issues in a situation, he or she will respond solely out of self-interest. However, to be morally imaginative, one cannot stop merely at the recognition of moral issues within a situation, but rather the 
individual must engage in additional processes that create alternative solutions to a situation. It is the unique convergence of these abilities that results in moral imagination. Thus, the key measurable and quantifiable criteria for this construct are the ability to identify any moral conflicts embedded within a situation, define the relevant stakeholders impacted by the circumstances, and develop a range of alternative solutions from a moral perspective.

This conceptualization goes beyond simply defining moral imagination as an innate trait one possesses. Instead, moral imagination can best be thought of as a unique cognitive process that an individual applies when making a decision. As such, moral imagination is theoretically and ontologically distinct from recent operationalizations of other individual difference variables that have been shown to influence ethical decision-making (e.g., moral awareness, Reynolds 2006; moral sensitivity, Sparks and Hunt 1998). Rather than portraying moral imagination as a personal characteristic, this cognitive framing of moral imagination allows for the possibility that it can be selectively exercised by individuals with every decision they face and influenced by intra-individual factors (Werhane 1998, 1999, 2002).

In this vein, much research has investigated person-related correlates of morality. For example, intelligence has been known to be a powerful explanatory variable of moral judgment for some time. Early reviews of the cognitive ability-morality relationship provide evidence of a substantial positive association (Chassell 1935; Kingsbury 1936), and more recent empirical work corroborates these assertions (Cohn and Westenberg 2004; Loviscky et al. 2007; Wells and Schminke 2001). Together, results such as these clearly indicate that cognition underlies the development of moral judgment skills that involve reasoning with increasingly complex moral dilemmas. Thus, change over time from less advanced modes of thinking to more advanced forms represents an important element in cognitive explanations of moral judgment. In all, because reasoning at the more advanced stages of moral development is more complex, cognitive ability is thought to be a necessary, but not sufficient, condition for moral judgment (Narvaez 1993).

Additionally, other researchers have highlighted the role of emotion as a powerful contributor to the decision-making process (e.g., Loewenstein et al. 2001; Vohs et al. 2007). Recent debates in the extant morality literature have focused on the precedence of emotion over cognitive processing, with some arguing that when it comes to morality, emotions play the primary causal role (e.g., Haidt 2001), and others have defended the role of higher-order reasoning as the critical causal determinant of moral judgment (e.g., Pizarro and Bloom 2003). That is, while deliberate cognitive processes do affect moral judgment, some argue that the dominance of effortful reasoning is attenuated by empirical evidence indicating that much processing of morality-laden scenarios is initiated prior to conscious thought (e.g., Bargh and Ferguson 2000). According to this perspective, emotion is thought to underlie cognition and guide behavior in a general sense. In effect, emotion underscores to the morally salient features of our environment by capturing attention and serving as a catalyst for logical reflection and moral motivation (Greenspan and Shanker 2004). For example, Haidt (2000), in his social intuitionist model of moral judgment, suggests that moral judgments often suddenly and effortlessly appear in consciousness, without any conscious awareness of having gone through the steps of searching, weighing evidence, or inferring a conclusion.

While the question of the primacy of emotions over reason in affecting judgment is outside the scope of this study, it is important to note that individual differences in chronic emotional states do tend to influence the effortful processing of morally relevant aspects of the situation. For example, in the context of decision-making, Lerner and Keltner (2001) showed that fearful individuals favor deliberation and safety, whereas anger leads to less analysis and more risktaking. In addition, disgust sensitivity has been linked to thinking styles (differences in the propensity to rely on intuition versus deliberation; Bartels 2008). These results are consistent with the view that emotions play an important role in determining moral judgment and that individual differences impact the extent to which emotional reactions are incorporated into judgments (Nichols and Mallon 2006).

The intuition versus deliberation debate notwithstanding recent research has begun to investigate how moral judgments are pre-consciously guided and influenced by an individual's conceptual schemata related to morality. The extent to which a given situation is coded as morally relevant seems to depend on individuals' idiosyncratic mapping of the moral domain and their tendency to see the world in moral terms (Lapsley and Narvaez 2004; Reynolds 2008). For instance, if an individual does not encode a situation as moral, there may be little motivation to act according to moral standards or exert effort in generating viable, mutually beneficial solutions in that particular situation.

\section{Determinants of Moral Imagination}

\section{Moral Attentiveness}

Organizational scholars have long argued that the primary catalyst of ethical decision-making is the ability to recognize that a moral issue exists in a given situation (Jones 1991; Rest 1986). In accordance with these assertions, moral imagination researchers propose that in order to initiate the moral imagination process, it is required that one must first interpret a situation as ethically significant in order to exercise moral imagination (Johnson 1993; 
Werhane 1998). Only after identification of a moral problem can individuals establish morality as an important element in the decision-making process and ultimately engage in a moral action. To date, many studies have suggested that individuals vary in their ability to recognize moral issues (Butterfield et al. 2000; Cohen et al. 2004; Reynolds 2006), suggesting that individuals differ in the amount of attention they devote to morality and moral matters.

SCT provides a theoretical basis for examining and understanding the role of individual differences in one's ability to recognize moral issues. Grounded in the work of Bandura (1977, 1986), SCT poses that human behavior is determined by the triadic interaction of individual cognition, actual behaviors, and the environment. While not discounting the traditional behaviorist notion that behavior is a response to raw, objective stimuli within the environment, SCT argues that behavior is also filtered and controlled largely by cognitive processes which idiosyncratically construct and color an individual's perceptions of reality (Jones 1989). Thus, not all aspects of environmental stimuli are processed when one is faced with making a situational decision, rather certain elements are ignored and others are selectively attended to (Fiske and Taylor 1991). When an individual engages the decision-making process, they begin by encoding (i.e., processing and taking into their cognition) pieces of information from the environment. However, the relevance of contextual information is based on the salience and vividness of the incoming stimuli as well as the accessibility of the cognitive framework used to identify and process incoming information.

Based on Fiske and Taylor's (1991) framework and research on moral awareness (Rest 1986; Butterfield et al. 2000), Reynolds (2008) recently developed and validated a quasi-personality trait known as moral attentiveness, the extent to which an individual perceives morality and moral elements in his or her experiences. According to its operational definition, moral attentiveness influences the extent to which one proactively screens stimuli for morally relevant information and constructs moral issues based on the accessibility of one's cognitive framework for morality. Those that have more chronically accessible frameworks for morality are simply more apt to interpret any given situation as morality-laden. It is in this sense that moral attentiveness can be distinguished from other moralitybased individual difference variables; moral attentiveness does not assume specific foci. Instead, it assumes that any and all stimuli may be morally relevant to the individual. Over a series of studies, Reynolds (2008) found that morality is a specific cognitive category that serves as a chronically accessible framework that makes an individual perceptually and reflectively attentive to moral matters. During construct validation, Reynolds demonstrated that the attention one pays to moral stimuli shapes a variety of moral behaviors (e.g., the recall/reporting of moral experiences and charitable giving).

Because moral attentiveness is a critical prerequisite for an individual to define the moral issues embedded in a situation, we argue that moral attentiveness should be an important precursor to engagement in the moral imagination process. According to Fiske and Taylor (1991), increased attention to morality increases the accessibility of salient and vivid stimuli. Accordingly, individuals that are more sensitive to moral issues in general will be more likely to engage in cognitive processes that focus on identifying impacted stakeholders and generating alternatives that positively influence others beyond themselves. Those that do not encode, or become attentive to, the moral issues in a situation will not be able to generate such behavioral alternatives. Extending this logic, we propose:

Hypothesis 1 Moral attentiveness will be positively related to moral imagination.

\section{Employee Creativity}

Given that moral imagination requires cognition beyond simply attending to moral issues in a situation, but also involves generating alternative solutions and recognizing the impact of those potential solutions on others (Werhane 1998, 1999, 2002), an individual's creative cognitive capacity may also impact the ability to demonstrate moral imagination. Although ethical cognition can be attributed to schema-based personality characteristics that direct one's ascription of importance to moral issues, we argue that one's level of creativity will be associated with moral imagination and should augment the influence of moral attentiveness on its expression.

Creativity is a complex phenomenon and as such, it has been variously defined. Most definitions, however, encompass two requirements. First, a "creative", person must generate novel or original ideas, and second, those ideas must be judged as valuable, useful, or unique by appropriate observers (Amabile 1996; Czikszentmihalyi 1996; Simonton 1996). While there is debate regarding whether creativity is a cognitive ability to be demonstrated, or a personality trait that is/is not possessed (i.e., Cattell 1971; Halpin et al. 1974), for purposes of this article, we employ the cognitive conceptualization of the construct.

Although research suggests that creativity is an important factor in the creation of effective organizations and managers (Mott 1972; Scratchley and Hakstain 2001), solutions to complex interpersonal problems (Plucker and Renzulli 1999), and even a healthy society (Mumford and Gustafson 1988), very little research has empirically investigated the influence of creativity on ethical decision- 
making. Empirical evidence for the link between creativity and moral reasoning was demonstrated by Mumford et al. (2010). Importantly, they hypothesized and established this relationship by including not just the generation if ideas as the basis of creative thinking but also the ability and capacity to identify implications of decisions. In all, they argue that the potential for creative thinking should provide an individual with the capacity to see many more alternative courses of action than non-creative individuals.

Another recent study by Bierly et al. (2009) applied Forsyth's (1992) personal moral philosophy model and demonstrated positive links between creativity and idealism (an individual's concern for others) and creativity and relativism (a tendency to rely on idiosyncratic decisionmaking processes and reject the use of cognitive scripts in moral dilemmas). The authors argue that highly creative people are likely "situationists," individuals who are intent on analyzing situational specifics during decisionmaking (especially in ambiguous circumstances), yet are guided largely by an ethic of harm avoidance (Forsyth 1980). Their results indicate that creativity does influence moral decision-making when one encounters unique and complex moral issues and, from a social cognitive perspective, suggest that creative individuals are able to maintain two particular goals when faced an ethical dilemma: they strive to ensure harm avoidance and they employ non-constrained thinking when evaluating an ethical situation.

Others have applied similar reasoning, arguing that creativity may represent a type of preconscious automaticity that impacts how an individual cognitively responds to an ethically charged situation (Narvaez and Lapsley 2005). As such, creativity can be described as an automatic, goal-directed activation of schemas or scripts (i.e., harm avoidance and non-constrained thinking) outside of conscious awareness resulting from a triggering event (i.e., an ethical dilemma).

In this vein, business ethics theorists postulate that creativity may interact with increased attention to morality (i.e., moral attentiveness) to facilitate the moral imagination process (Johnson 1993; Werhane 1998, 1999, 2002). One is capable of making ethical decisions to the extent that moral schemas are chronically accessible for social information processing (Fiske and Taylor 1991); however, to more fully exercise moral imagination, moral attentiveness in the presence of creativity anchors the possibilities one creates in a moral schema. In the context of decision-making, creativity allows the individual to generate more behavioral alternatives and more fully imagine the harm and benefit that could result from each option. Thus, once a moral issue has been identified, creativity should augment one's ability to articulate alternatives, empathetically imagine how others will experience these alternatives, and consider their possible ramifications on the interests of others. Thus, we propose the following:

Hypothesis 2A Employee creativity will be positively associated with moral imagination.

Hypothesis 2B The positive association between moral attentiveness and moral imagination will be moderated by employee creativity such that this link will be stronger for highly creative employees.

\section{Method}

\section{Participants}

Participants included 253 employed undergraduate students from a midsize, Midwestern university who received extra course credit for their participation in the study. To participate, individuals must have been working at least part time and willing to give permission for the researchers to contact their supervisors. Participants' supervisors were contacted via email and surveyed regarding the target subordinate. Subordinates whose supervisors did not participate were excluded from further analysis. Supervisors returned a total of 162 surveys, yielding a response rate of

$64.03 \%$.

The average age of the subordinate participants was 24.2 years old, with a mean tenure of approximately 28.5 months. The sample was $51.7 \%$ female, $92.3 \%$ Caucasian, $5.5 \%$ African-American, and $2.2 \%$ classified themselves as Asian American, Hispanic American, or Other.

The average age of the supervisors was 42.9 years, with an average management tenure of approximately 8 years. Supervisors had, on average, supervised the target employee for 24 months. The supervisor sample was $61.7 \%$ female, $88.3 \%$ Caucasian, $2.5 \%$ African-American, and the remaining $9.2 \%$ identified themselves as Asian American, Hispanic American, or Other.

\section{Procedure and Design}

An online survey was created and all data collection was done via the Internet in a laboratory setting. Upon accessing the survey website, participants first read a brief overview of the study. Because of the potential to influence responses in a socially desirable manner, the description of the study did not specifically indicate that the topic being examined was "moral imagination." Rather, the study was framed as a general exploration of organizational decisionmaking.

Once participants completed measures designed to assess demographic information, they were administered 
an online version of the Wonderlic Personnel Test (WPT) (to be used as a control variable) and then asked to fill out survey measures designed to tap their levels of moral attentiveness. Subsequent to this, participants were asked to read two business vignettes and respond to a series of questions afterward. Answers to these questions were coded and used to establish participants' scores for moral imagination. Upon survey completion, subordinates completed a consent form allowing their supervisors to be contacted. The supervisor survey assessed levels of focal employee creativity and supervisor demographic information.

\section{Measures}

\section{Dependent Variables}

Moral Imagination In order to gauge employee moral imagination, scenarios describing two business dilemmas were created. For the purposes of this study, we sought to control for the effects of moral intensity by constructing and employing scenarios representing situations characterized by high-moral intensity (Appendix). Jones (1991) proposed that moral intensity, the extent of issue-related imperative in a given situation, is likely to influence the amount of effort expended during cognitive processing, in part by increasing attributions of responsibility to oneself for the decision's likely consequences to others. Indeed, this assertion has received some empirical support in vignette-based studies (e.g., May and Pauli 2002; Nill and Schibrowsky 2005; Paolillo and Vitell 2002). Recent research indicates that the predominant element comprising moral intensity is the expected harm (expressed as a high likelihood of immediate, substantial, and long-ranging harm) that may befall the target character in the vignette (Kish-Gephart et al. 2010; McMahon and Harvey 2007). Using these operational criteria, the vignettes were each worded to reflect a high degree of moral intensity. Each vignette was pilot tested on a sample of 62 representative students who indicated that expected harm was very likely in each scenario. ${ }^{2}$ For each vignette, participants were asked to read a scenario that described a specific business dilemma, envision that they were in a position to make a decision on the situation and asked to respond to the following three questions:

\footnotetext{
${ }^{2}$ For pilot-testing purposes, participants were asked to rate how likely it was that immediate, substantial, and long-ranging harm would befall the victim in each scenario. Responses were rated on a 1-5 (Not at All Likely-Extremely Likely) scale. Results indicate that participants found a high likelihood of harm for each scenario (mean for Scenario $1=4.47$; mean for Scenario $2=4.28$ ).
}

1. List as many ways as you can think of to take action on this situation.

2. Describe the underlying moral issues that are important to consider when deciding on which of the above actions to take in this situation.

3. Identify who you think will be impacted by your decision and how they will be impacted.

Given that vignette-based measures result in openended responses, coding was necessary to transform the qualitative data generated into scores that could be used for subsequent statistical analysis. Three coders were used to rate the number of possible actions that respondents reported, the number of underlying moral issues reported, and the number of entities impacted by his/her decision. In order to facilitate a shared mental model surrounding the coding scheme, all coders were extensively trained. Coders then independently rated practice responses from 40 participants who participated in a pilot study. An initial estimate of interrater agreement from the pilot study sample was found to be marginal (ICC $=0.73$ ). After conferring to discuss the disagreements among the ratings using a consensus process, coders were given participant responses from the focal sample to code independently. Interrater agreement for the three raters on responses from the focal participant sample was acceptable (ICC $=0.92$ ). Following obtainment of sufficient agreement levels, the aggregate score from the three ratings was used as a measure of moral imagination for each participant and each scenario.

\section{Independent Variables}

Moral Attentiveness Moral attentiveness was measured using 12 items developed by Reynolds (2008) that tap the extent to which individuals recognize and consider moral matters in everyday experience. A sample item $(a=0.89)$ reads "I often find myself pondering about ethical issues."

Creativity We measured creativity by adapting a 5-item scale used in previous studies (Zhou and George 2001). Each employee's supervisor rated the extent to which he/ she agreed that each of the five behaviors was characteristic of the employee being rated. Supervisor ratings are widely used and are accepted in the creativity and innovation literature (Van der Vegt and Janssen 2003; Zhou and Shalley 2003). Sample items are "This employee is a good source of creative ideas" and "This employee often has a fresh approach to problems." We averaged responses to the five items to create the creativity measure (Cronbach's $a=0.96$ ).

Control variables. The influence of age, gender, race, and organizational tenure on ethical perceptions and 
behaviors represent fairly stable and consistent relationships noted in the research literature (Finkelstein and Hambrick 1990; Franke et al. 1997; Henle et al. 2005). As such, all participants were asked to provide their age, gender, ethnicity, and tenure with their organization.

In addition, because intelligence has been found to influence the capacity for moral reasoning (Chassell 1935; Cohn and Westenberg 2004; Loviscky et al. 2007; Wells and Schminke 2001), we included cognitive ability as a covariate. For this study, cognitive ability was measured with the WPT. Designed as a speeded test, the WPT is a 12-min timed test consisting of 50 multiple-choice and short-answer items that tap verbal ability, numerical ability, general knowledge, and spatial relations. Test scores range from 1 to 50, and adult working-class norms indicate a mean score of 21.75 with a standard deviation of 7.6 (Wonderlic, Inc. 2002). Internal consistency reliabilities range from 0.88 to 0.94 , test-retest values range from 0.82 to 0.94 , and alternate form estimates range from 0.73 to 0.95 (Wonderlic, Inc. 2002).
Results

Descriptive Statistics

Table 1 provides the descriptive statistics and zero-order correlations for the variables used to test our hypotheses.

Tests of Hypotheses

The hierarchical moderated multiple regressions used to test Hypotheses 1-2B are shown in Table 2. The test of Hypotheses 1 occurs in Step 2 of Table 2. As shown, the standardized regression coefficients were significant for moral attentiveness for both scenarios (Scenario 1: $b=0.46, p W 0.01$; Scenario 2: $b=0.33, p W 0.01$ ). These results support Hypothesis 1. Similarly, the standardized regression coefficients for employee creativity were significant for both scenarios (Scenario 1: $b=0.22$, $p W 0.01$; Scenario 2: $b=0.23, p W 0.01$ ), supporting Hypothesis 2A. The moral attentiveness 9 employee

Table 1 Means, standard deviations, and zero-order correlations of all study variables

\begin{tabular}{|c|c|c|c|c|c|c|c|c|c|}
\hline & 1 & 2 & 3 & 4 & 5 & 6 & 7 & 8 & 9 \\
\hline \multicolumn{10}{|l|}{ 1. Gender } \\
\hline 2. Age & -0.06 & & & & & & & & \\
\hline 3. Race & 0.01 & -0.01 & & & & & & & \\
\hline 4. Tenure & 0.13 & $0.35^{* *}$ & 0.01 & & & & & & \\
\hline 5. Cognitive ability & -0.06 & $-0.21 * *$ & -0.10 & -0.08 & & & & & \\
\hline 6. Moral attentiveness & 0.01 & -0.13 & 0.03 & -0.08 & $0.34 * *$ & & & & \\
\hline 7. Moral imagination (Scenario 1) & 0.04 & -0.04 & -0.09 & 0.09 & $0.38 * *$ & $0.49 * *$ & & & \\
\hline 8. Moral imagination (Scenario 2) & 0.07 & -0.12 & -0.10 & 0.06 & $0.35^{* *}$ & $0.33 * *$ & $0.62 * *$ & & \\
\hline 9. Creativity & -0.02 & -0.10 & 0.04 & $0.15^{t}$ & $0.33 * *$ & $0.40 * *$ & $0.39 * *$ & $0.30 * *$ & \\
\hline Mean & 1.08 & 24.16 & 1.09 & 28.38 & 23.15 & 3.11 & 8.29 & 8.06 & 3.71 \\
\hline SD & 0.50 & 6.90 & 0.39 & 27.53 & 5.59 & 0.74 & 3.16 & 2.63 & 1.01 \\
\hline
\end{tabular}

${ }^{\mathrm{t}} p \mathrm{~W} 0.10 ; * * p \mathrm{~W} 0.01$

Table 2 Hierarchical moderated multiple regression results

${ }^{\mathrm{t}} p \mathrm{~W} 0.10 ; * p \mathrm{~W} 0.05$; ** $p W 0.01$

\begin{tabular}{|c|c|c|c|c|c|c|}
\hline \multirow[t]{2}{*}{ Regression step } & \multicolumn{3}{|c|}{ Moral imagination (Scenario 1) } & \multicolumn{3}{|c|}{ Moral imagination (Scenario 2) } \\
\hline & $\overline{R^{2}}$ & $\mathrm{D} R^{2}$ & $b$ & $\overline{R^{2}}$ & $\mathrm{D} R^{2}$ & $b$ \\
\hline \multicolumn{7}{|l|}{ Step 1} \\
\hline Gender & 0.15 & & $0.14^{\mathrm{t}}$ & 0.19 & & $0.17 *$ \\
\hline Age & & & -0.12 & & & -0.11 \\
\hline Race & & & -0.06 & & & $-0.17 *$ \\
\hline Tenure & & & 0.08 & & & 0.07 \\
\hline Cognitive ability & & & $0.22 * *$ & & & $0.23^{* *}$ \\
\hline \multicolumn{7}{|l|}{ Step 2} \\
\hline Moral attentiveness & 0.46 & 0.31 & $0.45 * *$ & 0.33 & 0.14 & $0.34 * *$ \\
\hline Creativity & & & $0.22 * *$ & & & $0.23 * *$ \\
\hline \multicolumn{7}{|l|}{ Step 3} \\
\hline Creativity 9 Moral attentiveness & 0.51 & 0.05 & $0.14^{*}$ & 0.33 & 0.00 & 0.02 \\
\hline
\end{tabular}




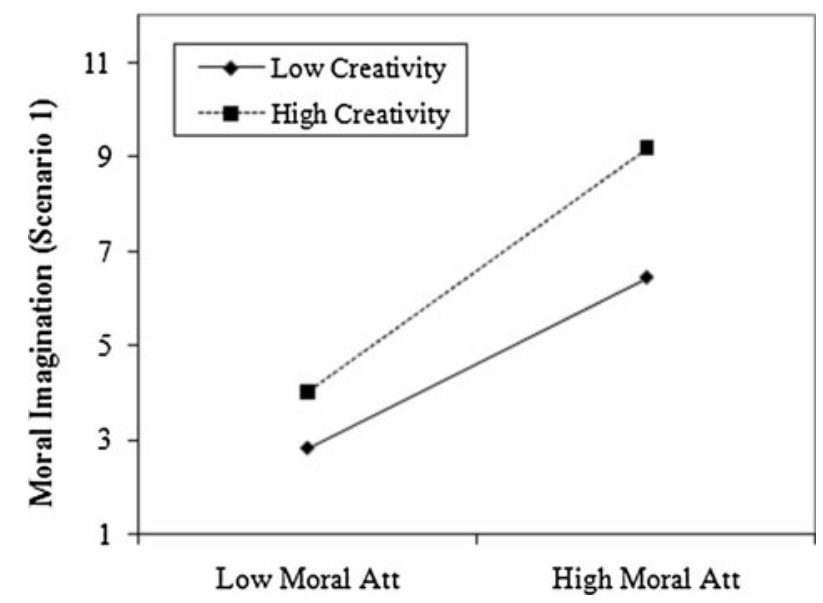

Fig. 1 The interaction of moral attentiveness and creativity on moral imagination

creativity interaction term added significant incremental variance at Step 3 for Scenario $1(b=0.14, p W 0.01)$, which is plotted in Fig. 1 at one standard deviation around the centered mean (Aiken and West 1991). In order to more fully understand the nature of the interaction, we tested the differences in slopes using the $Z$-test for correlated associations (Meng et al. 1992). As hypothesized, the link between moral attentiveness and moral imagination is stronger for more creative employees than those rated less creative by supervisors $(z=3.49, p W 0.05)$. The moral attentiveness 9 creativity interaction term failed to attain significance for Scenario $2(b=0.02, p=n s)$, providing partial support for Hypothesis $2 \mathrm{~B}$.

\section{Discussion}

The hypotheses for this study were largely supported. In accordance with our theoretical framework, we found that moral attentiveness positively influences one's moral imagination. Furthermore, we found partial support for the augmenting effects of employee creativity on the relationship between moral attentiveness and moral imagination.

In practical application, our results reveal that individuals who chronically perceive and consider morality and moral elements in everyday experiences are more likely to imaginatively discern various moral possibilities for acting in a given situation. These findings lend support to the body of work done by a variety of scholars suggesting that ethical decision-making begins with (or is at least impacted by) an individual's ability to recognize moral issues in a situation (Butterfield et al. 2000; Jones 1991; Rest 1986;

Reynolds 2008).

Given the relationship between moral attentiveness and moral imagination, these findings have implications for employee training as well as broader organizational change efforts. Because of the increasing societal pressure on businesses to behave ethically and responsibly, it seems increasingly prudent for organizational decision-makers to thoughtfully consider and selectively place into key management positions those who are cognitively inclined toward morality and with a view toward a more ethical culture within their organizations. For morally attentive individuals, topics that center on ethics are consistent with their world- view. To the extent that morally attentive individuals are identified and placed in strategically pivotal positions, they could foster an ethical environment and provide the energy necessary for organizational ethics initiatives to be successful (Brass et al. 1998). Practically speaking, such initiatives can be achieved by setting, communicating, and managing performance according to clear ethical standards, conducting periodic ethics audits, and sharing feedback with employees in such a manner as to stimulate discussion and employee input into goal-setting. Leaders can also conduct ethics training sessions, help devise clear codes of ethical conduct, and institute programs for rewarding ethical con- duct within their organizations. Thus, a critical element for building and sustaining momentum for such ethics-related change efforts may lie in an organization's ability and willingness to recognize morally attentive employees and put them in positions of authority.

Our results also indicate that employee creativity not only has main effects on moral imagination, but also strengthens the association between moral attentiveness and moral imagination. Creativity may enable individuals to develop complex solutions to difficult ethical problems (Buchholz and Rosenthal 2005). Creative and imaginative people tend to use cognitive processes that are consistent with higher levels of moral development, which may lead to a higher level of ethics and more innovative consideration of the problem at hand (Buchholz and Rosenthal 2005; Teal and Carroll 1999). Based on our results, the implementation of development programs meant to influence employee creativity may be wise.

The organizational context is an important determinant investigated by many scholars in the area of creativity (Amabile 1996; Ekvall 1997; Oldham and Cummings 1996; Shalley et al. 2000). Indeed, many companies now emphasize the importance of creativity by instituting creativity management programs. In attempting to create and facilitate an effective organizational culture of creativity and innovation, building an organizational learning culture is of critical necessity (Dweck 2000; Dweck and Leggett 1988; Redmond et al. 1993). To create a productive organizational learning culture, leaders in organizations should openly support continued learning opportunities, foster a harmonious and collaborative organizational culture, and provide timely and accurate developmental feedback (Steelman et al. 2004). 
In doing so, they should also consider carefully the roles of supervisors and managers within the organization. Research has demonstrated that employee creativity will flourish when supervisors apply transformational leadership principles (Jaussi and Dionne 2003; Shin and Zhou 2003). For example, managerial behaviors likely to foster favorable conditions for the development of creativity include creative role-modeling, instructing employees on creativity-relevant skills, the provision of hands-on opportunities to apply these skills, offering support and encouragement, and the provision of a clear visionary direction.

According to Werhane (1999), many of the ethical mistakes managers make are due to a paucity of moral imagination. In all, our results suggest that morally attentive individuals have a better-developed sense of moral imagination, suggesting that they generate behavioral options that are not provincially embedded in a restricted context and have a capacity for reframing the problem from various perspectives. Additionally, our results indicate that one's creativity can augment the influence of moral attentiveness on moral imagination. A capacity for creativity may enable individuals to develop a more extensive set of context-independent, novel alternatives to the problem that can be morally justified. Contending with ethical issues requires careful application of principles and weighing of moral considerations. In an organizational context, when faced with an ethically charged business- related decision, employees must be able to understand the social, economic, organizational, and personal factors that are at play, an awareness of how moral conflicts might unfold, and an ability to envision outcomes that benefit all stakeholders mutually (Vidaver-Cohen 1997). Higher lev- els of creativity may help the individual understand dis- similar characters, situations, or experiences in the context of moral decisionmaking (Werhane 1999).

From a theoretical perspective, our mixed results across scenarios are intriguing. Whereas we found full support for our hypotheses using the first scenario, expected relationships were non-significant using the second. While not the focus of this study, these results suggest that respondents may have differentially weighted each scenario according to perceived moral intensity, which in turn set a precedent for moral imagination.

As conceptualized, moral imagination is a conscious, voluntary cognitive process and, as such, its activation may be at the discretion of the decision-maker (Caldwell and Moberg 2007; Moberg and Seabright 2000; Werhane 1998, 1999, 2002). Based on Jones (1991), this decision may rest on the level of moral intensity attributed to the situation, which is itself informed by a variety of situational characteristics and how individuals respond to those elements. For example, our first scenario dealt with pregnancy, making one of the "victims" an unborn child. To the degree that social norms dictate that no harm come to the unborn (perhaps illustrated by Jones' notion of social consensus - the degree of peer agreement that an action is wrong), the overall moral intensity of the situation may increase, guiding deeper moral cognitive processing for our first scenario.

In addition, our scenarios differed in terms of the gender of the victim, which may be a particularly salient situational consideration depending on the gender of the respondents. Relational demography has been found to increase liking, trust, and favoritism (Bauer and Green 1996; Turban and Jones 1988), suggesting that demographic similarity may influence the level of cognitive effort respondents are willing to exert in order to generate mutually beneficial outcomes. Future research should consider how embedded contextual cues influence scripts for moral reasoning, how and to what extent moral issues can be made salient to employees, and whether doing so affects ethical decision-making.

In a related vein, several studies have shown that, within a business context, people generally rely on lower levels of moral judgment than they would in other settings (Carpendale and Krebs 1995; Marnburg 2001; Weber 1990) and that some occupations (e.g., accounting) select and socialize newcomers to reason at a lower level of morality (Abdolmohammadi et al. 2003). Results such as these may be interpreted to mean that managers, executives, and accountants have lower moral reasoning abilities than other populations. An alternative explanation, and one that is consistent with the concept of moral imagination, is that moral judgment is a fluid rather than static capacity and that it can be employed differentially depending on contextual cues and constraints. Future research should empirically examine the extent to which occupational choice influences moral imagination and, perhaps more importantly, the direction of causality for this association.

Further, moral judgment in general has been found to be associated with moral action in many studies predicting both positive (e.g., helping, whistle-blowing, and resistance to pressure from authority figures) and negative (e.g., cheating and stealing) behaviors (see Greenberg 2002; Rest and Narvaez 1994; Thoma 1994; Treviño 1992). Future research should investigate the influence of moral imagination on such discrete behaviors to determine if the moral imagination construct accounts for incremental variance in the prediction of important outcomes or serves as an

indirect influence on the moral judgment-behavior link.

\section{Limitations}

Although our findings have helped to answer recent calls in the ethics literature, our study did have several limitations. 
For example, one limitation of this study was our use of a student sample, which limits generalizability. While our sample was composed of older student employees with more work experience than traditional college students, use of this sample may have nevertheless restricted the range on relevant job-related variables. For example, our sample had an average tenure of 2 years and 4 months. If any of the constructs under study preferentially require a significant amount of time on the job to form associations, our findings may be artificially enhanced or attenuated. Future researchers should attempt to replicate our results on older, full-time employees with more experience in the workforce to ensure the generalizability of our findings. In a related vein, while the sample size was large enough to conduct our analyses, future studies of these constructs should be applied to larger samples to test the reliability of current findings.

Another limitation that must be acknowledged involves the employed measures. Specifically, the measures for moral imagination were vignette-based type of measurement which assumes a level of situational fidelity some find questionable (Morrison et al. 2004). While we do assume that respondents understood the vignettes and responded appropriately, one might further argue that reactions to such scenarios pose an artificial measure of the cognitive process being investigated. Additionally, in the case of scenario-based research, ethical situations may be defined too briefly for the respondent to evaluate or may fail to capture the complexity of issues faced in an actual employment setting, in turn potentially limiting participant responses (Maclagan 1995; Randall and Gibson 1990). Because the limited scope of issues covered in vignettes may fail to capture the breadth of the moral experience, future research should consider a wider range of situations in the workplace. Our vignettes are focused on employee behavior and corporate policy. However, it is likely that situations pertaining to other issues (e.g., corporate ethics on a more strategic scale) would elicit differing participant responses. Moreover, other measures such as participant observations, in depth interviewing, and longitudinal studies may supplement scenario-based research to provide an even clearer understanding of the decision-making process that individuals use when faced with a potentially challenging ethical situation.

We also wish to emphasize that our hypothesis testing was conducted in a cross-sectional manner, which limits the extent that causality can be assessed. In particular, future research should focus on identifying the antecedents that contribute to the formation of moral imagination, which have received little research attention to date. Determining these antecedents would make it easier for researchers to design longitudinal studies that focus on the processes that influence its expression. Eventually, interventions may be implemented designed to improve moral imagination.

Finally, research within the cognitive neuroscience domain has convincingly demonstrated that emotions arise when we respond to a wide range of morally significant events (Kaplan et al. 2007; Moll et al. 2003; Sanfey et al. 2003), suggesting that emotions may serve as a catalyst for moral motivation. Although some have argued for the dominance of intuitive emotion for moral functioning (e.g., Haidt 2001), others have criticized the intuitionist perspective as limited in its emphasis on naïve intuition rather than well-formed deliberation that relies on cognitive structures devoted to the interpretation and processing of moral issues (Narvaez 2010). While the current study took the perspective of cognitive theorists who argue that one must first view an issue as falling within the moral domain in order to engage moral judgment processes (Nucci 2004; Rest 1986), the empirical evidence supporting the influence of emotions on moral judgment certainly merits future research investigating the joint influence of emotions and cognition on moral imagination as one considers how one's actions could impact the interests, welfare, and reactions of others.

\section{Appendix}

\section{Scenario \#1}

Four months ago, a co-worker left and your office has been extremely overworked. Furthermore, due to a hiring freeze across the company, the vacancy has not been filled. You have been working long overtime hours (without overtime pay) trying to make up the slack that has occurred due to this vacancy. These long hours have begun to take a toll on you and your family who feels like your increased time away from home is having a negative impact on everyone. Good news just came down from your supervisor. The hiring freeze has been lifted and you can begin to recruit applicants to fill the position.

After a successful round of interviews with applicants, your supervisor has made a selection, but wants your input on the final hire. When he tells you who his first choice is, you are immediately concerned. The woman he wants to hire is pregnant. You discovered this by accident when you overheard her talking on her cell phone in the hallway after her interview. You are fairly confident your boss does not know she is expecting and you know she is not required to tell a potential employer that she is pregnant. You cannot help but worry that you will spend the next 6 months training her and after such time, she will go on maternity leave or worse, quit. Then you will be stuck once again trying to fill into make up the slack. Your boss asks you for your opinion on the candidate. 


\section{Scenario \#2}

One of your coworkers recently ran into some hard times. His wife has lost her job and his family (which includes five children) has been having considerable financial problems. In order to make some extra money, he has recently started painting houses for additional income. In order to make people aware of his new business, he has been using the company's e-mail account and telephone to schedule jobs and communicate with customers regarding job deadlines, payment, and other related details. In addition, he has placed the company's e-mail address and telephone number on his personal business cards that he has been distributing.

A few times over the last month, he has called in sick. Because he has been calling in frequently, some of his work has not been getting done and, as a result, other employees (including you) have had to step into fulfill his job duties. However, because he never appears to be under the weather, you suspect that he has been using sick days to get painting work done.

\section{References}

Abdolmohammadi, M., Read, W., \& Scarbrough, D. (2003). Does selection-socialization help to explain accountants' weak ethical reasoning? Journal of Business Ethics, 42, 71-81.

Aiken, L. S., \& West, S. G. (1991). Multiple regression: Testing and interpreting interactions. Thousand Oaks: Sage.

Amabile, T. M. (1996). Creativity in context. Boulder, CO: Westview Press.

Anand, V., Ashforth, B., \& Joshi, M. (2004). Business as usual: The acceptance and perpetuation of corruption in organizations. Academy of Management Executive, 18, 39-55.

Andreoli, N., \& Lefkowitz, J. (2009). Individual and organizational antecedents of misconduct in organizations. Journal of Business Ethics, 85, 309-332.

Ashkanasy, N. M., Windsor, C. A., \& Treviño, L. K. (2006). Bad apples in bad barrels revisited: Cognitive moral development, just world beliefs, rewards, and ethical decision-making. Business Ethics Quarterly, 16, 449-474.

Bandura, A. (1977). Social learning theory. Englewood Cliffs, NJ: Prentice-Hall.

Bandura, A. (1986). Social foundations of thought and action. Englewood Cliffs, NJ: Prentice-Hall.

Bargh, J. A., \& Ferguson, M. J. (2000). Beyond behaviorism: On the automaticity of higher mental processes. Psychological Bulletin, $126,925-945$.

Bartels, D. M. (2008). Principled moral sentiment and the flexibility of moral judgment and decision making. Cognition, 108, $381-417$

Bauer, T. N., \& Green, S. G. (1996). Development of leader-member exchange: a longitudinal test. Academy of Management Journal, 30, 1538-1567.

Bierly, P., Kologinsky, R., \& Charette, B. (2009). Understanding the complex relationship between creativity and ethical ideologies. Journal of Business Ethics, 86, 101-112.
Brass, D. J., Butterfield, K. D., \& Skaggs, B. C. (1998). Relationships and unethical behavior: A social network perspective. Academy of Management Journal, 23, 14-31.

Bright, D. S., Fry, R. E., \& Cooperrider, D. L. (2006). Transformative innovations for the mutual benefit of business society, and environment. BAWB Interactive Working Paper Series, 1, 17-31.

Buchholz, R., \& Rosenthal, S. (2005). The spirit of entrepreneurship and the qualities of moral decision making: Toward a unifying framework. Journal of Business Ethics, 60, 307-315.

Butterfield, K. D., Trevino, L., \& Weaver, G. (2000). Moral awareness in business organizations: Influences of issue-related and social context factors. Human Relations, 53, 982-1018.

Caldwell, D., \& Moberg, D. (2007). An exploratory investigation of the effect of ethical culture in activating moral imagination. Journal of Business Ethics, 73, 193-204.

Cameron, K., Dutton, J., \& Quinn, R. (2003). Positive organizational scholarship. San Francisco: Berrett-Koehler Publishers.

Carpendale, J. I. M., \& Krebs, D. L. (1995). Variations in moral judgment as a function of type of dilemma and moral choice. Journal of Personality, 63, 289-313.

Cattell, R. B. (1971). Abilities: Their structure, growth, and action. Boston: Houghton Mifflin.

Chassell, C. (1935). The relation between morality and intellect. New York: Teachers College Press.

Cohen, J., Pant, L., \& Sharp, D. (2004). An examination of differences in ethical decision-making between Canadian business students and accounting professionals. Journal of Business Ethics, 30, 319-336.

Cohn, L. D., \& Westenberg, P. M. (2004). Intelligence and maturity: Meta-analytic evidence for the incremental and discriminant validity of Loevinger's measure of ego development. Journal of Personality and Social Psychology, 86, 760-772.

Czikszentmihalyi, M. (1996). Creativity. New York: Harper Collins.

Dweck, C. S. (2000). Self-theories: Their role in motivation, personality, and development. Lillington, NC: Taylor \& Francis.

Dweck, C. S., \& Leggett, E. L. (1988). A social-cognitive approach to motivation and personality. Psychological Review, 95, 256-273.

Ekvall, G. (1997). Organizational conditions and levels of creativity. Creativity and Innovation Management, 6, 195-205.

Fesmire, S. (2003). John Dewey and moral imagination: Pragmatism in ethics. Bloomington, IN: Indiana University Press.

Finkelstein, S., \& Hambrick, D. C. (1990). Top-management-team tenure and organizational outcomes: The moderating role of managerial discretion. Administrative Science Quarterly, 35, 484-503.

Fiske, S. T., \& Taylor, S. E. (1991). Social cognition. New York: Random House.

Forsyth, D. R. (1980). A taxonomy of ethical ideologies. Journal of Personality and Social Psychology, 39, 175-184.

Forsyth, D. R. (1992). Judging the morality of business practices: The influence of personal moral philosophies. Journal of Business Ethics, 11, 461-470.

Franke, G. R., Crown, D. F., \& Spake, D. F. (1997). Gender differences in ethical perceptions of business practices: A social role theory perspective. Journal of Applied Psychology, 82, 920-934.

Frederick, W. C. (2000). Pragmatism, nature and norms. Business and Society Review, 105, 467.

Godwin, L. (2006). Creating mutual beneficial possibilities: Theorizing factors that impact an individual's capacity for moral imagination. BAWB Interactive Working Paper Series 1(1), 32-46. Available online at: http://worldbenefit.case.edu/research/ paperseries $/ ? \mathrm{p}=20$.

Greenberg, J. (2002). Who stole the money, and when? Individual and situational determinants of employee theft. Organizational Behavior and Human Decision Processes, 89, 985-1003. 
Greenspan, S. I., \& Shanker, S. (2004). The first idea: How symbols, language and intelligence evolved from our primate ancestors to modern humans. Boston: Da Capo Press, Perseus Books.

Haidt, J. (2000). The emotional dog and its rational tail: A social intuitionist approach to moral judgment. Psychological Review, $108,814-834$.

Haidt, J. (2001). The emotional dog and its rational tail. Psychological Review, 108, 814-834.

Halpin, G., Halpin, G., \& Torrance, E. P. (1974). Relationships between creative thinking abilities and a measure of the creative personality. Educational and Psychological Measurement, 34, $75-82$.

Henle, C. A., Giacalone, R. A., \& Jurkiewicz, C. L. (2005). The role of ethical ideology in workplace deviance. Journal of Business Ethics, 56, 219-230.

Jaussi, K., \& Dionne, S. (2003). Leading for creativity: The role of unconventional leader behavior. The Leadership Quarterly, 14, 475-498.

Johnson, M. (1993). Moral imagination: Implications of cognitive science for ethics. Chicago: University of Chicago Press.

Jones, J. (1989). Personality and epistemology: Cognitive social learning theory as a philosophy of science. Zygon, 24, 23-38.

Jones, T. M. (1991). Ethical decision making by individuals in organizations: An issue-contingent model. Academy of Management Review, 16, 366-395.

Kant, I. (1970). Critique of pure reason (N. K. Smith, Trans.). London, UK: Macmillan (originally published 1781).

Kaplan, J. T., Freedman, J. T., \& Iacoboni, M. (2007). Us versus them: Political attitudes and party affiliation influence neural responses to faces of presidential candidates. Neuropsychologia, $45,55-64$.

Kingsbury, F. (1936). The relation between morality and intellect: A compendium of evidence contributed by psychology, criminology, and sociology. Psychological Bulletin, 33, 842-844.

Kish-Gephart, J. J., Harrison, D. A., \& Trevino, L. K. (2010). Bad apples, bad cases, and bad barrels: Meta-analytic evidence about sources of unethical decisions at work. Journal of Applied Psychology, 95, 1-31.

Kohlberg, L. (1976). Moral stages and moralization: The cognitivedevelopmental approach. In T. Lickona (Ed.), Moral development and behavior: Theory, research, and social issues (pp. 31-53). New York: Holt, Reinhart \&Winston.

Krebs, D. L., \& Denton, K. (2005). Toward a more pragmatic approach to morality: A critical evaluation of Kohlberg's model. Psychological Review, 112, 629-649.

Lapsley, D. K., \& Narvaez, D. (2004). Moral development, self and identity. Mahwah, NJ: Lawrence Erlbaum Associates.

Lerner, J. S., \& Keltner, D. (2001). Fear, anger, and risk. Journal of Personality and Social Psychology, 81, 146-159.

Loewenstein, G. F., Weber, E. U., Hsee, C. K., \& Welch, N. (2001). Risk as feelings. Psychological Bulletin, 127, 267-286.

Loviscky, G. E., Trevinio, L. K., \& Jacobs, R. R. (2007). Assessing managers' ethical decision-making: An objective measure of managerial judgment. Journal of Business Ethics, 73, 263-285.

Luthans, F., \& Avolio, B. J. (2009). The "point" of positive organizational behavior. Journal of Organizational Behavior, 30, 291-307.

Maclagan, P. (1995). Ethical thinking in organisations. Management Learning, 26, 159-177.

Marcus, B., \& Schuler, H. (2004). Antecedents of counterproductive behavior at work: A general perspective. Journal of Applied Psychology, 89, 647-660.

Marnburg, E. (2001). The questionable use of moral development theory in studies of business ethics: Discussion and empirical findings. Journal of Business Ethics, 32, 275-283.
May, D. R., \& Pauli, K. P. (2002). The role of moral intensity in ethical decision making: A review and investigation of moral recognition, evaluation, and intention. Business and Society, 41, 84-117.

McMahon, J. M., \& Harvey, R. J. (2007). The effect of moral intensity on ethical judgment. Journal of Business Ethics, 72, $335-357$

Meng, X., Rosenthal, R., \& Rubin, D. B. (1992). Comparing correlated correlation coefficients. Psychological Bulletin, 111, $172-175$.

Moberg, D. J., \& Seabright, M. (2000). The development of moral imagination. Business Ethics Quarterly, 10, 845-884.

Moll, J., de Oliveirra-Souza, R., \& Eslinger, P. (2003). Morals and the human brain: A working model. NeuroReport, 14, 299-305.

Morrison, R., Stettler, K., \& Anderson, A. (2004). Using vignettes in cognitive research on establishment surveys. Journal of Official Statistics, 20, 319-340.

Mott, P. E. (1972). The characteristics of effective organizations. New York: Harper \& Row.

Mumford, M., \& Gustafson, S. (1988). Creativity syndrome: Integration, application and innovation. Psychological Bulletin, $103,27-43$.

Mumford, M. D., Waples, E. P., Antes, A. L., Brown, R. P., Connelly, S., Murphy, S. T., et al. (2010). Creativity and ethics: The relationship of creative and ethical problem-solving. Creativity Research Journal, 22, 74-89.

Narvaez, D. (1993). High achieving students and moral judgment. Journal for the Education of the Gifted, 16(3), 268-279.

Narvaez, D. (2010). Moral complexity: The fatal attraction of truthiness and the importance of mature moral functioning. Perspectives on Psychological Science, 5, 163-181.

Narvaez, D., \& Lapsley, D. (2005). The psychological foundations of everyday morality and moral expertise. In D. Lapsley \& C. Power (Eds.), Character psychology and character education (pp. 140-165). Notre Dame, IN: University of Notre Dame Press.

Nichols, S., \& Mallon, R. (2006). Moral dilemmas and moral rules. Cognition, 100, 530-542.

Nill, A., \& Schibrowsky, J. A. (2005). The impact of corporate culture, the reward system, and perceived moral intensity on marketing students' ethical decision making. Journal of Marketing Education, 27, 68-80.

Nucci, L. (2004). Reflections on the moral self construct. In D. K. Lapsley \& D. Narvaez (Eds.), Moral development, self, and identity (pp. 111-132). Mahwah, NJ: Lawrence Erlbaum Associates.

Oldham, G. R., \& Cummings, A. (1996). Employee creativity: Personal and contextual factors. Academy of Management Journal, 39, 607-635.

Paolillo, J. G. P., \& Vitell, S. J. (2002). An empirical investigation of the influence of selected personal, organizational, and moral intensity factors on ethical decision making. Journal of Business Ethics, 35, 65-74.

Pizarro, D. A., \& Bloom, P. (2003). The intelligence of the moral intuitions: A reply to Haidt (2001). Psychological Review, 110, 193-196.

Plucker, J. A., \& Renzulli, J. S. (1999). Psychometric approaches to the study of human creativity. In R. J. Sternberg (Ed.), Handbook of creativity (pp. 35-61). Cambridge, England: Cambridge University Press.

Randall, D. M., \& Gibson, A. M. (1990). Methodology in business ethics research: A review and critical assessment. Journal of Business Ethics, 9, 457-471.

Redmond, M. R., Mumford, M. D., \& Teach, R. (1993). Putting creativity in work: Effects of leader behavior on subordinate 
creativity. Organizational Behavior and Human Decision Processes, 55, 120-151.

Rest, J. R. (1986). Moral development: Advances in research and theory. New York: Praeger.

Rest, J. R., \& Narvaez, D. (Eds.). (1994). Moral development in the professions: Psychology and applied ethics. Hillsdale, NJ: Lawrence Erlbaum Associates.

Reynolds, S. J. (2006). Moral awareness and ethical predispositions: Investigating the role of individual differences in the recognition of moral issues. Journal of Applied Psychology, 91, 233-243.

Reynolds, R. (2008). Moral attentiveness: Who pays attention to the moral aspects of life? Journal of Applied Psychology, 93, 1027-1041.

Sanfey, A. G., Rilling, J. K., Aronson, J. A., Nystrom, L. E., \& Cohen, J. D. (2003). The neural basis of decision-making in the ultimatum game. Science, 300, 1755-1758.

Scratchley, L., \& Hakstain, A. (2001). The measurement and prediction of managerial creativity. Creativity Research Journal, 13(3\&4), 367-384.

Sekerka, L., Bagozzi, R., \& Charnigo, R. (2009). Facing ethical challenges in the workplace: Coneptualizing and measuring professional moral courage. Journal of Business Ethics, 89, 565-579.

Seligman, M. E. P., Steen, T., Park, N., \& Peterson, C. (2005). Positive psychology progress: Empirical validation of interventions. American Psychologist, 60, 410-421.

Shalley, C. E., Gilson, L. L., \& Blum, T. C. (2000). Matching creativity requirements and the work environment: Effects on satisfaction and intentions to leave. Academy of Management Journal, 43, 215-224.

Shin, S. J., \& Zhou, J. (2003). Transformational leadership, conservation, and creativity: Evidence from Korea. Academy of Management Journal, 46, 703-714.

Simonton, D. K. (1996). Creativity in personality, developmental and social psychology: Any links with cognitive psychology? In T. B. Ward \& S. M. Smith (Eds.), Creative thought, an investigation of conceptual structures and processes (pp. 309-324). Washington, DC: American Psychological Association.

Smith, A. (1977). An inquiry into the nature and causes of the wealth of nations. Chicago, IL: University of Chicago Press (original publication 1776)

Sparks, J. R., \& Hunt, S. (1998). Marketing researcher ethical sensitivity: Conceptualization, measurement, and exploratory investigation. Journal of Marketing, 62, 92-109.

Steelman, L. A., Levy, P. E., \& Snell, A. F. (2004). The feedback environment scales (FES): Construct definition, measurement and validation. Educational and Psychological Measurement, 64, 165-184.

Teal, E. J., \& Carroll, A. B. (1999). Moral reasoning skills: Are entrepreneurs different? Journal of Business Ethics, 19, 229240.

Thoma, S. J. (1994). Moral judgments and moral action. In J. R. Rest \& D. Narvaez (Eds.), Moral development in the professions: Psychology and applied ethics (pp. 199-211). Hillsdale: Erlbaum Associates.
Treviño, L. K. (1992). Moral reasoning and business ethics: Implications for research, education, and management. Journal of Business Ethics, 11, 445-459.

Treviño, L. K., \& Brown, M. E. (2004). Managing to be ethical: Debunking five business ethics myths. Academy of Management Executive, 18, 69-83.

Treviño, L. K., \& Weaver, G. R. (2001). Organizational justice and ethics program "follow-through:" Influences on employees' harmful and helpful behavior. Business Ethics Quarterly, 11, 651-671.

Treviño, L. K., Weaver, G. R., \& Reynolds, S. J. (2006). Behavioral ethics in organizations: A review. Journal of Management, 32, 951-990.

Turban, D. B., \& Jones, A. P. (1988). Supervisor-subordinate similarity: Types, effects, and mechanisms. Journal of Applied Psychology, 73, 228-234.

Van der Vegt, G. S., \& Janssen, O. (2003). Joint impact of interdependence and group diversity on innovation. Journal of Management, 29, 729-751.

Vidaver-Cohen, D. (1997). Moral imagination in organizational problem-solving: An institutional perspective. Business Ethics Quarterly, 7, 1-26.

Vohs, K., Baumeister, R., \& Loewenstein, G. (2007). Do emotions help or hurt decision making? A hedgefoxian perspective. New York, NY: Russell.

Wagner, S., \& Dittmar, L. (2006). The unexpected benefits of Sarbanes-Oxley. Harvard Business Review, 4, 133-140.

Weber, J. (1990). Managers' moral reasoning: Assessing their responses to three moral Dilemmas. Human Relations, 43, 687-702.

Wells, D., \& Schminke, M. (2001). Ethical development and human resources training: An integrative framework. Human Resource Management Review, 11, 135-158.

Werhane, P. H. (1998). Moral imagination and the search for ethical decision-making in management. Business Ethics Quarterly, 1, 75-98.

Werhane, P. H. (1999). Moral imagination and management decisionmaking. New York: Oxford University Press.

Werhane, P. H. (2002). Moral imagination and systems thinking. Journal of Business Ethics, 38, 33-42.

Wonderlic, Inc. (2002). Wonderlic personnel test \& scholastic level exam user's manual. Libertyville, IL: Author.

Wright, T. A., \& Quick, J. C. (2009). The emerging positive agenda in organizations: Greater than a trickle, but not yet a deluge. Journal of Organizational Behavior, 30, 147-159.

Zhou, J., \& George, J. M. (2001). When job dissatisfaction leads to creativity: Encouraging the expression of voice. Academy of Management Journal, 44, 682-696.

Zhou, J., \& Shalley, C. (2003). Research on employee creativity: A critical review and directions for future research. In J. J. Martocchio \& G. R. Ferris (Eds.), Research in personnel and human resources management (Vol. 22, pp. 165-217). Oxford, England: Elsevier Science Ltd. 
